\title{
Enhanced performance of PID load frequency controller for power systems
}

Dola Gobinda Padhan, Suresh Kumar Tummala

EEE Department, Gokaraju Rangaraju Institute of Engineering and Technology, India

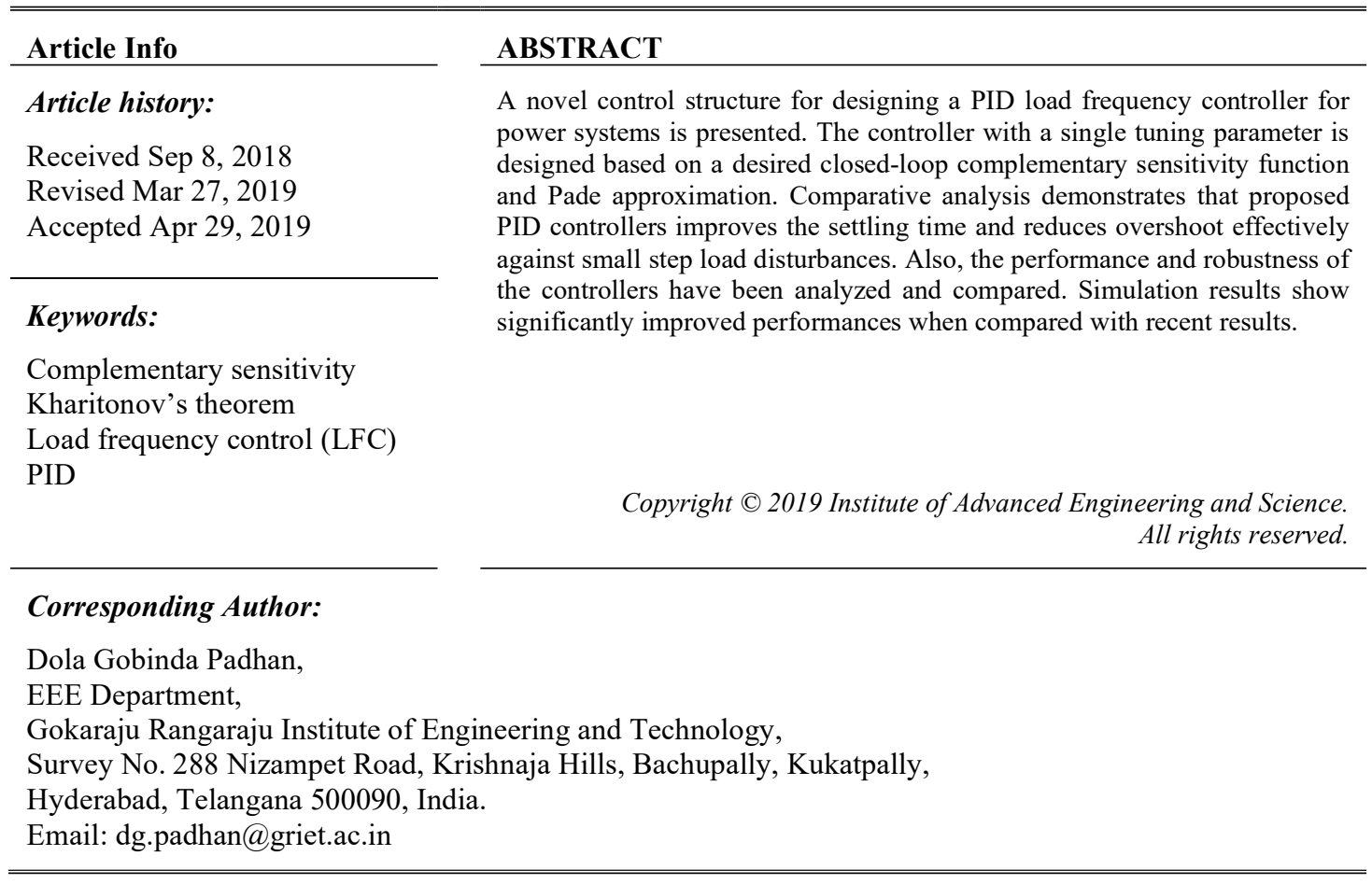

\section{INTRODUCTION}

Frequency deviation in Power System due to variation between generation and load shall be rectified within a fraction of seconds resulting in stability and security. Load Frequency Control (LFC) of an extensive power framework can be alluded as the issue of controlling the recurrence by directing the created units with reaction to change in stack [1]. For framework soundness, LFC must furnish recurrence with zero enduring state mistakes and tie-line trade varieties, high damping of recurrence motions and diminishing overshoot of the unsettling influence. The objectives specified are conveyed effectively in past works by various creators utilizing Fuzzy rationale PI and PID controllers [2, 3], ideal control [4, 5]. Variable structure control $[6,7]$, versatile and self-tuning control $[8,9]$. Down the line, different tuning rules have picked up the consideration for the previously mentioned goals in which Internal Model Control (IMC) [10] is one among them. The LFC PID controller configuration utilizing Laurent arrangement is clarified by Padhan and Majhi [11]. Double PI controller tuning utilizing swam enhancement calculation is introduced in [12]. The two-degree-of-freedom internal model control scheme suggested by Tan [10] consists of two controllers with two tuning parameters where simultaneous tuning of the two parameters is difficult. In practice, a simple control structure with a fewer number of tuning parameters is desirable. The proposed control structure (see Figure 1) for LFC design consists of only one controller $\left(\mathrm{G}_{\mathrm{c}}\right)$. Kasireddy et.al designed a PID controller for LFC through reduced model order [13]. 


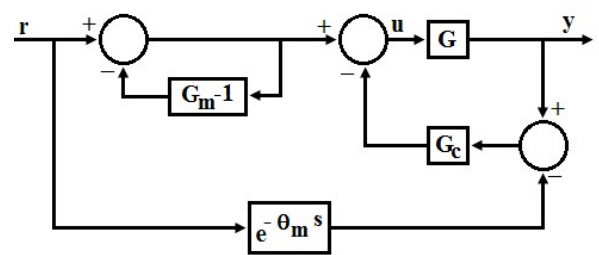

Figure 1. Proposed control structure

In Figure 1, $\mathrm{G}$ and $\mathrm{G}_{\mathrm{m}} \mathrm{e}^{-\theta \mathrm{m}}$ represent the power system dynamics and its model, respectively. For LFC, controller design is inconvenient because $G$ results in higher order plant models, which are approximated by lower order transfer functions with time delay using a relay-based identification method.

This paper has been alienated into 6 sections. Modeling of power system dynamics with necessary derivations discourse in section 2. In section 3, the PID controller design method is discussed followed by Section 4 in which the simulation results are presented. Section 5 deals with Robustness analysis and performance of a power system using Kharitonov's rectangles followed by conclusions in section 6 .

\section{MODELING OF POWER SYSTEM DYNAMICS}

Figure 2 shows single area power systems with a linear model. From Figure 2 it can be noticed that the power is supplied to the single area by a single generator. There are two types of turbine used for a generation: (a) non-reheated (NRT) and reheated (RT).

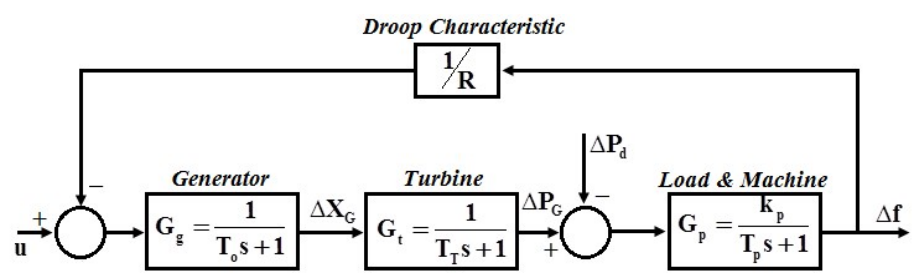

Figure 2. Single area power system

The plant model used for LFC without droop characteristics is

$$
G=G_{g} G_{t} G_{p}
$$

Where $G_{g}, G_{t}$, and $G_{p}$ are the dynamics of the governor, turbine, and load \& machine, respectively. For a reheated turbine,

$$
G_{t}=\frac{c T_{r} s+1}{\left(T_{r} s+1\right)\left(T_{T} s+1\right)}
$$

Where $T_{r}$ is a constant and $\mathrm{c}$ is the portion of the power generated by the reheat turbine in the total generated power. For non-reheated turbine $T_{r}=0$. The plant model used for LFC with droop characteristic is

$$
G=\frac{G_{g} G_{t} G_{p}}{1+\left(G_{g} G_{t} G_{p} / R\right)}
$$

From (1) and (2) can be represented by the second-order transfer function model 


$$
G=\frac{k e^{-\theta_{m} s}}{\left(T_{1} s+1\right)\left(T_{2} s+1\right)}
$$

State space equations in the Jordan canonical form become

$$
\begin{aligned}
& \dot{x}(t)=A x(t)+b u\left(t-\theta_{m}\right) \\
& y(t)=c x(t)
\end{aligned}
$$

Where

$$
A=\left[\begin{array}{cc}
\frac{-1}{T_{1}} & 0 \\
0 & \frac{-1}{T_{2}}
\end{array}\right] ; b=\left[\begin{array}{l}
1 \\
1
\end{array}\right] ; c=\frac{k}{T_{1}-T_{2}}\left[\begin{array}{ll}
1 & -1
\end{array}\right]
$$

When a relay test is performed with symmetrical relay of height $\pm \mathrm{h}$, then the expression for the limit cycle output for $0 \leq \mathrm{t} \leq \theta_{\mathrm{m}}$ is

$$
y(t)=c e^{A t} x(0)+c A^{-1}\left(e^{A t}-l\right) b h
$$

Let the half period of the limit cycle output be $\tau$. Then the expression for the limit cycle output for $\theta_{\mathrm{m}} \leq \mathrm{t} \leq \mathrm{T}$ is

$$
y(t)=c e^{A\left(t-\theta_{m}\right)} x\left(\theta_{m}\right)-c A^{-1}\left(e^{A\left(t-\theta_{m}\right)}-l\right) b h
$$

The condition for a limit cycle output can be written as

$$
y(0)=c x(0)=-y(\tau)=0
$$

Substitution of $\mathrm{t}=\mathrm{T}$ in (7) and use of (6) gives the initial value of the cycling states

$$
x(0)=\left(I+e^{A \tau}\right)^{-1} A^{-1}\left(2 e^{A\left(\tau-\theta_{m}\right)}-e^{A \tau}-I\right) b h
$$

When $t_{p}$ is the time instant at which the positive peak output occurs and $t_{p} \geq \theta_{m}$, then the expression of the peak output $A_{p}$ becomes

$$
A_{p}=c\left(e^{A\left(t_{p}-\theta_{m}\right)} x\left(\theta_{m}\right)-A^{-1}\left(e^{A\left(t_{p}-\theta_{m}\right)}-I\right) b h\right)
$$

and the expression for the peak time becomes

$$
t_{p}=\theta_{m}+\frac{T_{1} T_{2}}{T_{1}-T_{2}} \ln \left(\frac{1+e^{-\tau / T_{1}}}{1+e^{-\tau / T_{2}}}\right)
$$

Substitution of A, b, and c in (9) and (10) give

$$
\begin{aligned}
& T_{1}\left(1+e^{-\tau / T_{2}}\right)\left(2 e^{-\left(\tau-\theta_{m}\right) / T_{1}}-e^{-\tau / T_{1}}-1\right)-T_{2}\left(1+e^{-\tau / T_{1}}\right)\left(2 e^{-\left(\tau-\theta_{m}\right) / T_{2}}-e^{-\tau / T_{2}}-1\right)=0 \\
& A_{p}=k h\left(2\left(1+e^{-\tau / T_{1}}\right)^{\frac{-T_{1}}{T_{1}-T_{2}}}\left(1+e^{-\tau / T_{2}}\right)^{\frac{T_{2}}{T_{1}-T_{2}}}-1\right)
\end{aligned}
$$


The (11-13) are solved simultaneously to estimate $\theta_{m}, T_{1}$ and $T_{2}$ from the measurements of $\tau, A_{p}$ and $t_{p}$. The relentless state gain $\mathrm{k}$ is thought to be known from the earlier or can be assessed from a stage flag test. Care has been taken to explain the arrangement of non-direct conditions, so intermingling may not occur to a false arrangement.

\section{PID CONTROLLER DESIGN}

The nominal complementary sensitivity function for load disturbance rejection can be obtained as

$$
T=\frac{G G_{c}}{1+G G_{c}}
$$

To reject a step change in the load of the power system, the asymptotic constraint should be satisfied so that the closed loop internal stability can be achieved [3].

$$
\lim _{\mathrm{s} \rightarrow-\frac{1}{\mathrm{~T}_{1}},-\frac{1}{\mathrm{~T}_{2}}}(1-\mathrm{T})=0
$$

The desired closed-loop complementary sensitivity function is proposed as

$$
T=\frac{\left(\alpha_{2} s^{2}+\alpha_{1} s+1\right)}{(\beta s+1)^{4}} e^{-\theta_{m} s}
$$

Where $\beta$ is the only tuning parameter for obtaining the desired performance of the power system. As there always exists a trade-off between the nominal performance and robust performance, $\beta$ must be tuned according to the desired choice. $\alpha_{1}$ and $\alpha_{2}$ can be obtained from (15) and the constraint as

$$
\begin{aligned}
& \alpha_{1}=\frac{T_{1}^{2}\left(\left(1-\frac{\beta}{T_{1}}\right)^{4} e^{-\theta_{m} / T_{1}}-1\right)-T_{2}^{2}\left(\left(1-\frac{\beta}{T_{2}}\right)^{4} e^{-\theta_{m} / T_{2}}-1\right)}{T_{2}-T_{1}} \text { and } \\
& \alpha_{2}=T_{2}^{2}\left(\left(1-\frac{\beta}{T_{2}}\right)^{4} e^{-\theta_{m} / T_{2}}-1\right)+T_{2} \alpha_{1}
\end{aligned}
$$

Using (14), (15) and second order Pade' approximation for the time delay term, we get

$$
G_{c}=\frac{6\left(\alpha_{2} s^{2}+\alpha_{1} s+1\right)\left(I_{2} s^{2}+l_{1} s+1\right)}{k m_{o} s\left(\frac{m_{2}}{m_{o}} s^{2}+\frac{m_{1}}{m_{o}} s+1\right)}
$$

Where

$$
\begin{aligned}
& \mathrm{I}_{1}=\frac{\left(6 \mathrm{~T}_{2}+6 \mathrm{~T}_{1}+4 \theta_{\mathrm{m}}\right)}{6} \quad \mathrm{I}_{2}=\frac{\left(6 \mathrm{~T}_{1} \mathrm{~T}_{2}+4 \mathrm{~T}_{1} \theta_{\mathrm{m}}+4 \mathrm{~T}_{2} \theta_{\mathrm{m}}+\theta_{\mathrm{m}}^{2}\right)}{6} \\
& \mathrm{~m}_{0}=6 \theta_{\mathrm{m}}+24 \beta-6 \alpha_{1} \\
& \mathrm{~m}_{1}=36 \beta^{2}+\theta_{\mathrm{m}}^{2}-6 \alpha_{2}+16 \beta \theta_{\mathrm{m}}+2 \alpha_{1} \theta_{\mathrm{m}} \\
& \mathrm{m}_{2}=24 \beta^{2} \theta_{\mathrm{m}}+2 \alpha_{2} \theta_{\mathrm{m}}+4 \beta \theta_{\mathrm{m}}^{2}+24 \beta^{3}
\end{aligned}
$$

The (18) can be written in the form of a PID controller with lead/lag filter as 


$$
G_{c}=K_{c}\left(1+\frac{1}{T_{2} s}+T_{d} s\right)\left(\frac{a_{2} s^{2}+a_{1} s+1}{b_{2} s^{2}+b_{1} s+1}\right)
$$

Where

$$
\begin{aligned}
& \mathrm{K}_{\mathrm{c}}=\frac{6 \alpha_{1}}{\mathrm{~km}_{0}} \quad \mathrm{~T}_{\mathrm{i}}=\alpha_{1} \quad \mathrm{~T}_{\mathrm{d}}=\frac{\alpha_{2}}{\alpha_{1}} \\
& \mathrm{a}_{2}=\mathrm{I}_{2} \quad \mathrm{a}_{1}=\mathrm{l}_{1} \quad \mathrm{~b}_{2}=\frac{\mathrm{m}_{2}}{\mathrm{~m}_{0}} \quad \mathrm{~b}_{1}=\frac{\mathrm{m}_{1}}{\mathrm{~m}_{0}}
\end{aligned}
$$

\section{SIMULATION RESULTS}

Consider a power system with a non-reheated and a reheated turbine whose model parameters are given by $\mathrm{K}_{\mathrm{P}}=120, \mathrm{~T}_{\mathrm{P}}=20, \mathrm{~T}_{\mathrm{T}}=0.3, \mathrm{~T}_{\mathrm{G}}=0.08, \mathrm{R}=2.4, \mathrm{~T}_{\mathrm{r}}=4.2$ and $\mathrm{c}=0.35$ [11]. The identified models and controller settings (see Table 1) for the power system with non-reheated and reheated turbines are obtained using $(11-13,17)$. The Nyquist plots of the identified and actual models are shown in Figure 4 to illustrate the accuracy of the identification method. To get stable and robust response, $\beta$ values in Table 1 are obtained from extensive simulation studies. Figure 3 and Figure 5 show the frequency change of the power system following a load demand $\Delta \mathrm{P}_{\mathrm{d}}=0.01$. The stability robustness is tested by changing the parameters of the system by $50 \%$. From the simulation results, it is evident that the proposed method gives significantly

\begin{tabular}{|c|c|c|}
\hline Model Type & Identified Model & Control Parameters \\
\hline NRT (WD) & $\frac{120 \mathrm{e}^{-0.4626 \mathrm{~s}}}{(28.4952 \mathrm{~s}+1)(0.2202 \mathrm{~s}+1)}$ & $\begin{aligned} \mathrm{K}_{\mathrm{c}} & =2.0245, \mathrm{~T}_{\mathrm{i}}=0.5005, \mathrm{~T}_{\mathrm{d}}=0.1332, \mathrm{a}_{1}=29.0238, \\
\mathrm{a}_{2} & =15.1661, \mathrm{~b}_{1}=28.6982, \mathrm{~b}_{2}=5.77239, \beta=0.01\end{aligned}$ \\
\hline NRT (D) & $\frac{250 \mathrm{e}^{-0.05 \mathrm{~s}}}{2.028 \mathrm{~s}^{2}+12.765 \mathrm{~s}+106.2}$ & $\begin{array}{c}\mathrm{K}_{\mathrm{c}}=0.7192, \mathrm{~T}_{\mathrm{i}}=0.2075, \mathrm{~T}_{\mathrm{d}}=0.1159, \mathrm{a}_{\mathrm{l}}=0.9212 \\
\mathrm{a}_{2}=0.1411, \mathrm{~b}_{1}=0.1515, \mathrm{~b}_{2}=0.0234, \beta=0.07\end{array}$ \\
\hline RT (WD) & $\frac{120 \mathrm{e}^{-0.541 \mathrm{~s}}}{(23.2137 \mathrm{~s}+1)(0.9057 \mathrm{~s}+1)}$ & $\begin{aligned} & \mathrm{K}_{\mathrm{c}}=3.6549, \mathrm{~T}_{\mathrm{i}}=0.5797, \mathrm{~T}_{\mathrm{d}}=0.2355, \mathrm{a}_{\mathrm{l}}=24.4801, \\
& \mathrm{a}_{2}=29.7725, \mathrm{~b}_{1}=24.0884, \mathrm{~b}_{2}=20.2681, \beta=0.01\end{aligned}$ \\
\hline RT (D) & $\frac{235.3 \mathrm{e}^{-0.035 \mathrm{~s}}}{1.79 \mathrm{~s}^{2}+16.9 \mathrm{~s}+100}$ & $\begin{array}{c}\mathrm{K}_{\mathrm{c}}=1.0619, \mathrm{~T}_{\mathrm{i}}=0.2107, \mathrm{~T}_{\mathrm{d}}=0.1828, \mathrm{a}_{1}=1.154 \\
\mathrm{c}_{2}=0.1323, \mathrm{~b}_{1}=0.1973, \mathrm{~b}_{2}=0.0231, \beta=0.065\end{array}$ \\
\hline
\end{tabular}
improved performances than the Tan's method.

Table 1. Control parameters for identified model

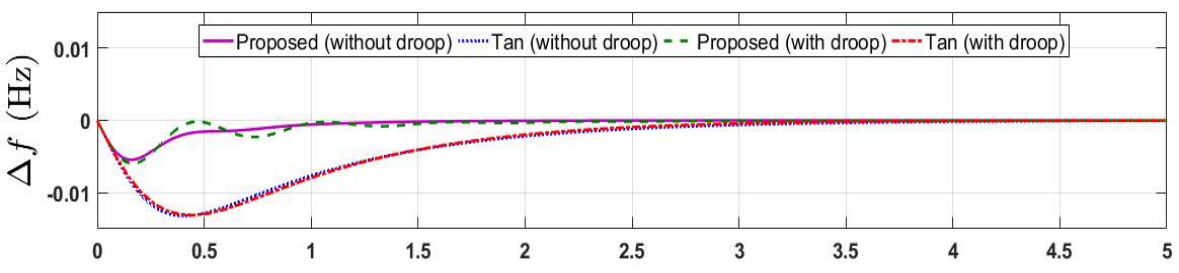

(a) Nominal systems

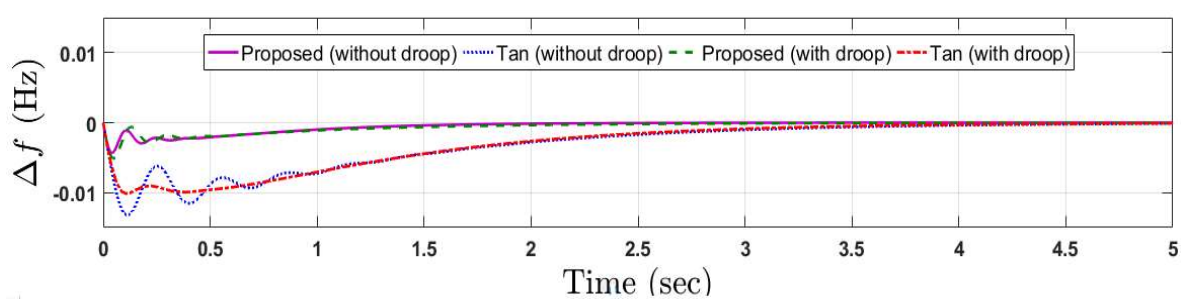

(b) Parameters of the system change by $50 \%$

Figure 3. Frequency deviation of the closed loop system with non-reheated turbine 


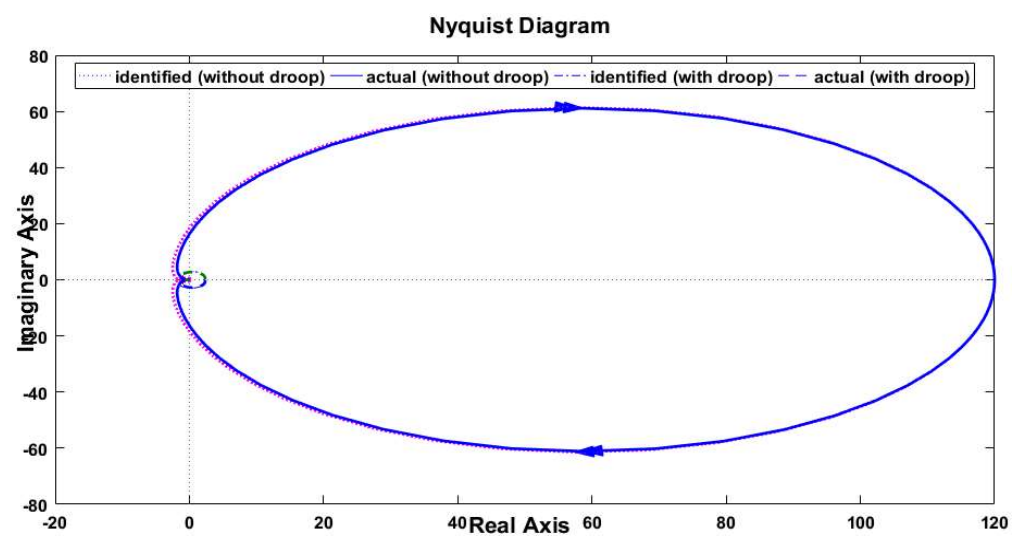

Figure 4. Nyquist plots for the power system with non-reheated turbine
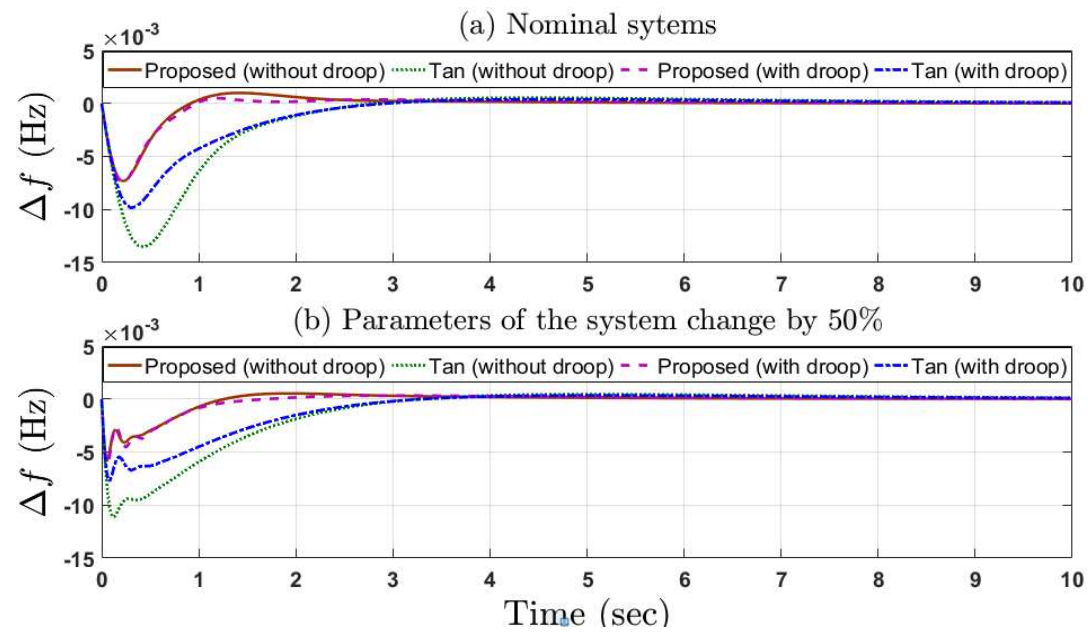

Figure 5. Frequency deviation of the closed loop system with reheated turbine

\section{ROBUSTNESS ANALYSIS AND PERFORMANCE}

In this section, Robustness of the system has been analyzed using Kharitonov's Theorem. Closedloop characteristic equation $\Delta_{C L}(s)$ and denominator of the closed-loop transfer function $T(s)$ are the polynomials that make the control system stable. Considering the forward-path and feedback-path transfer functions $\mathrm{G}(\mathrm{s})$ and $\mathrm{H}(\mathrm{s})$, characteristic equation is

$$
\begin{aligned}
& \Delta_{C L}(s)=1+G(s) H(s)=0 \\
& \Delta_{C L}(s)=a_{n} s^{n}+a_{n-1} s^{n-1}+\ldots \ldots+a_{1} s+a_{0}
\end{aligned}
$$

For simplicity, assume that the leading coefficient $a_{n}$ is constant and the coefficients have been normalized so that $a_{n}=1$. The polynomial coefficients can then be expressed as

$$
a_{i} \in\left[a_{i}^{\min }, a_{i}^{\max }\right], \quad i=0,1 \ldots \ldots . n-1
$$

so, the characteristic equation becomes

$$
\Delta_{C L}(s)=s^{n}+a_{n-1} s^{n-1}+\ldots \ldots+a_{1} s+a_{0}
$$


According to Kharitonov's Theorem, an nth-degree interval polynomial family described by (1a) and (1b) is robustly stable if and only if each of the four Kharitonov polynomials is stable, that is, all the roots of those polynomials have strictly negative real parts.

For the system

$$
G(s)=\frac{120}{(0.08 s+1)(0.3 s+1)(20 s+1)}
$$

The characteristic equation is

$$
\Delta_{\mathrm{CL}}(\mathrm{s})=0.48 \mathrm{~s}^{3}+7.624 \mathrm{~s}^{2}+20.38 \mathrm{~s}+121=0
$$

For $\pm 10 \%$ variations in the coefficients of the polynomial, The intervals of the polynomial will become

$$
a_{3} \in[0.528,0.432] \quad a_{2} \in[8.3864,6.8616] \quad a_{1} \in[22.418,18.342] \quad a_{0} \in[133.1,108.9]
$$

Figure 6 shows Kharitonov's rectangles rotate around the origin in a counter-clockwise direction to satisfy the monotonic phase increase property of Hurwitz polynomials. For clarity, the graph is zoomed in Figure 7 to show the zero-exclusion point. As the Kharitonov's rectangles do not pass through the origin, it is concluded that the closed loop system guarantees the robust stability.

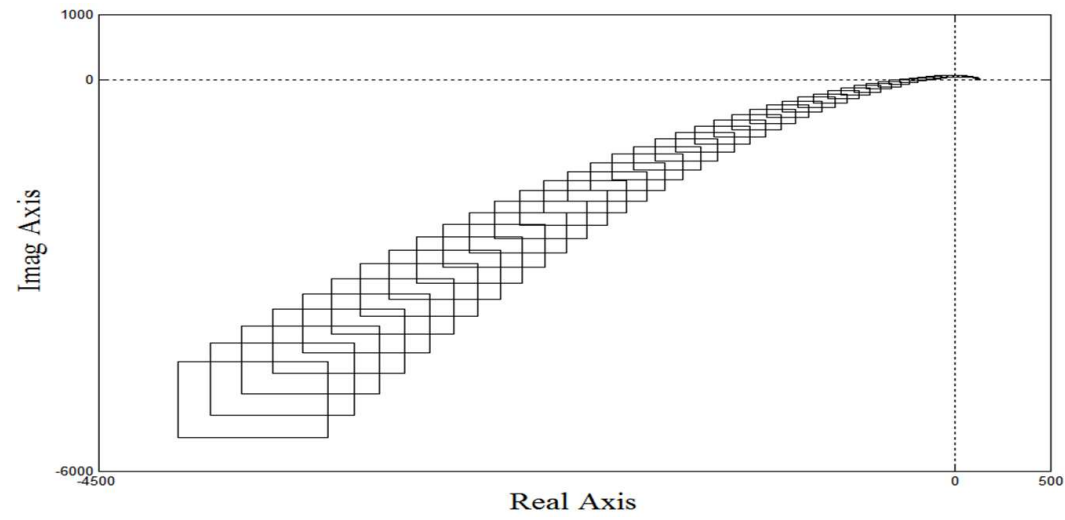

Figure 6 . Response of the system with $\pm 10 \%$ variations in the coefficients of polynomial on the complex plane

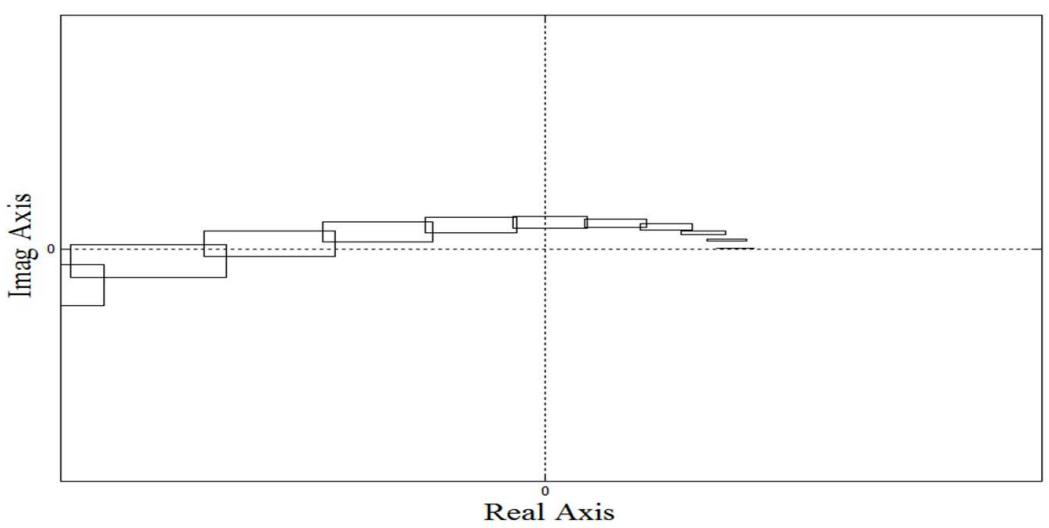

Figure 7. Response of the system showing zero exclusion point 
Table 2 shows it is observed that the proposed method gives less Integral Absolute Error (IAE), Integral Squared Error (ISE) and Integral Time Absolute Error (ITAE) as compared to Tan's method, so closed loop performance is improved. If we compare the total variations of the control signals, the results of both methods are almost same. Thus, with same control signals, the proposed method gives comparatively fewer errors.

Table 2. Various errors and total variations

\begin{tabular}{ccccc}
\hline Type of Model & $\begin{array}{c}\text { Integral Time } \\
\text { Absolute Error }\end{array}$ & $\begin{array}{c}\text { Integral Absolute } \\
\text { Error }\end{array}$ & $\begin{array}{c}\text { Integral Squared } \\
\text { Error }\end{array}$ & Total variations \\
\hline NRT (WD)-Tan & 0.5164 & 0.1061 & 0.001494 & 0.0199 \\
NRT (WD)-Proposed & 0.5147 & 0.1008 & 0.001184 & 0.0127 \\
NRT (D)-Tan & 0.5303 & 0.106 & 0.001363 & 0.0214 \\
NRT (D)-Proposed & 0.521 & 0.1007 & 0.001175 & 0.0189 \\
RT (WD)-Tan & 2.002 & 0.2007 & 0.002254 & 0.0735 \\
RT (WD)-Proposed & 2.058 & 0.2061 & 0.002273 & 0.07906 \\
RT (D)-Tan & 2.006 & 0.2007 & 0.01223 & 0.0729 \\
RT (D)-Proposed & 1.966 & 0.2006 & 0.002264 & 0.0797 \\
\hline
\end{tabular}

\section{CONCLUSION}

The Load Frequency Characteristics of a single-area power system with non-reheated and reheated turbines have been deliberated. The proposed method is flexible and gives satisfactory performance in nominal as well as the perturbed case. The proposed PID controller with a new control structure and a single tuning parameter $(\beta)$ gave better performance than Tan's controller. By showing the zero exclusion point by Kharitonov's rectangles, it guarantees the robust stability for closed loop power systems. The proposed scheme can easily be extended to multi-area power systems.

\section{REFERENCES}

[1] R. K. Cavin, M. C. Budge, and P. Rasmussen, "An optimal linear system approach to load frequency control," IEEE Trans. Power App. Systems, vol. 90(6), pp. 2472-2482, 1971.

[2] C. E. Fosha and O. I. Elgerd, "The megawatt-frequency control problem: A new approach via optimal control theory," IEEE Trans. Power App. Systems, vol. 89(4), pp. 563-567, 1972.

[3] N. N. Bengiamin and W. C. Chan, "Variable structure control of electric power generation," IEEE Trans. Power App. Systems, vol. 101(2), pp. 376-380, 1982.

[4] M. A. Sheirah and M. M. Abd-EI-Fattah, "Improved load frequency self-tuning regulator.," Int. J. Control, vol. 39(1), pp. 143-158, 1984.

[5] P. Kundur, Power System Stability and Control. McGraw Hill, New York 1994.

[6] C. T. Pan and C. M. Liaw, "An adaptive controller for power system load-frequency control," IEEE Trans. Power Systems, vol. 4(1), pp. 122-128, 1989.

[7] J. Talaq and F. Al-Basri, "Adaptive fuzzy gain scheduling for load frequency control," IEEE Trans. Power Systems, vol. 14(1), pp. 145-150, 1999.

[8] M. F. Hossain, T. Takahashi, M. G. Rabbani, M. R. I. Sheikh, and M. Anower, "Fuzzy-proportional integral controller for an AGC in a single area power system," Proc. 4th Int. Conf. Electrical and Computer Engineering, Dhaka, Bangladesh, pp. 120-123, 2006.

[9] S. Majhi, "Relay based identification of processes with time delay," Journal of process control, vol. 17, pp. 93-101, 2007.

[10] W. Tan, "Unified tuning of PID load frequency controller for power systems via IMC," IEEE Transactions on Power Systems, vol. 25(1), pp. 341-350, 2010.

[11] D. G. Padhan and S. Majhi, "A New Control Scheme for PID Load Frequency Controller of Single-area and Multiarea Power Systems," ISA Transactions, vol. 52, pp. 242-251, 2013.

[12] M. Elsisi, M. Soliman, M. A. S. Aboelela, and W. Mansour, "Dual Proportional integral controller of Two-Area Load Frequency control based gravitational search algorithm," Telkomnika Indonesian Journal of Electrical Engineering and Computer Science, vol. 15(3), pp. 397-406. 2015.

[13] Idamakanti Kasireddy, Abdul Wahid Nasir, and Arun Kumar Singh., "Non-integer IMC based PID design for load frequency control of power system through reduced model order," International Journal of Electrical and Computer Engineering, vol. 8(2), pp. 837-844, 2018. 